\title{
The Ingenious Mast Cell: Contemporary insights into mast cell behavior and function
}

\author{
Joakim Dahlin ${ }^{1}$, Marcus Maurer ${ }^{2}$, Dean Metclafe ${ }^{3}$, Gunnar Pejler ${ }^{4}$, Ronit Sagi-Eisenberg ${ }^{5}$, \\ and Gunnar Nilsson ${ }^{1}$ \\ ${ }^{1}$ Karolinska Institutet \\ ${ }^{2}$ Charité Universitätsmedizin Berlin \\ ${ }^{3}$ NIAID \\ ${ }^{4}$ Uppsala Universitet \\ ${ }^{5}$ Tel Aviv University Sackler Faculty of Medicine
}

October 28, 2020

\begin{abstract}
Mast cells are (in)famous for their role in allergic diseases, but the physiological and pathophysiological roles of this ingenious cell are still not fully understood. Mast cells are important for homeostasis and surveillance of the human system, recognizing both endogenous and exogenous agents, which induce release of a variety of mediators acting on both immune and non-immune cells, including nerve cells, fibroblasts, endothelial cells, smooth muscle cells and epithelial cells. During recent years, clinical and experimental studies on human mast cells as well as experiments using animal models have resulted in many discoveries that help decipher the function of mast cells in health and disease. In this review we focus particularly on new insights into mast cell biology, with a focus on mast cell development, recruitment, heterogeneity and reactivity. We also highlight the development in our understanding of mast cell driven-diseases and discuss the development of novel strategies to treat such conditions.
\end{abstract}

\section{Introduction}

Although hematopoietic stem cells produce mast cell (MC) progenitors, mature MCs are normally absent in blood while found in almost all tissues as highly granulated cells. The stem cell factor (SCF) receptor, KIT, is one of the most critical receptors on mature mast cells, as a reduction in KIT signaling leads to mast cell deficiency. Yet, signaling through the receptor is redundant for early development of mast cell progenitors in peripheral blood ${ }^{1}$. MCs are equipped with a great number of receptors enabling them to sense and react to a diversity of stimuli ${ }^{2}$. The most studied receptor that causes MC activation is the high-affinity IgE receptor, FceRI. Another receptor that has received particular attention during recent years is the Masrelated G protein-coupled receptor X2 (MRGPRX2), a G-protein coupled receptor recognizing a variety of pharmacologic agents (tubocurarine, atracurium, icatibant, ciprofloxacin) causing pseudo allergic reactions 3,4. MRGPRX2 also serves as receptor for substance P, components of insect venom, antimicrobial peptides, secreted eosinophil products and other cationic peptides ${ }^{5,6}$. Other receptors that induce IgE-independent MC activation include the IL-33 receptor, which is important for MCs to recognize cell injury and trauma 7 as well as regulating IgE-mediated responses ${ }^{8-10}$, and pattern recognition receptors (PRRs) sensing "danger " signals, including microbes ${ }^{11}$. When MCs sense an endogenous or exogenous agent through binding to one of their many activating receptors, they react by releasing mediators through three major pathways (Figure 1). The most rapid response is exocytosis of secretory granules (SGs) and the release of preformed mediators such as histamine, proteases and heparin ${ }^{12}$. This is accompanied by the de novobiosynthesis of lipid mediators, predominantly prostaglandin D2 (PGD2) and the cys-leukotrienes LTC4, LTD4 and LTE4, 
but also other lipid mediators like thromboxane A2 (TXA2) and 15-HETE ${ }^{13}$. MCs also have the capacity to synthesize a number of cytokines, chemokines, growth factors and interferons ${ }^{14}$. Notably, release of de novo -synthesized mediators can take place without preceding degranulation ${ }^{15}$. Thus, MCs can be activated and produce lipid mediators and/or cytokines in the absence of detectable degranulation (by histology or measurement of granule mediators). Finally, MCs also secrete extracellular vesicles including exosomes. MC exosomes can transfer proteins, enzymes, and RNA that can be taken up by other cells, either proximal to the secreting MC or located at distant sites ${ }^{16-18}$ (www.exocarta.org) (Figure 1). Notably, patients with systemic mastocytosis have increased levels of exosomes with a MC signature including constitutively activated KIT, enabling transfer of mutant proteins to other cells ${ }^{19}$.

Given the broad distribution of MCs and their multifunctional role, they have been implicated in many diseases beyond allergy ${ }^{20-22}$. For example, recent reviews highlight the role of MCs in cardiovascular diseases ${ }^{23}$, cancer $^{24}$, airway diseases ${ }^{25}$, as well as in viral, bacterial and fungal infections ${ }^{26-28}$. Even if MCs commonly are discussed in the context of disease, it is important to remember that they also have a role in homeostasis, the initiation of acute inflammation ${ }^{29}$ and in the protection against danger, whether it comes from the outside (venoms, pathogens, etc.) or from within the body (cell injury etc.) ${ }^{30}$.

In this review we highlight some of the most recent findings regarding MC origin and development, recruitment, heterogeneity and reactivity, MC disease, new therapeutic possibilities, and animal models to study MC biology.

\section{The origin of mast cells}

Hematopoietic cells arise in several temporally distinct waves during prenatal development. The first MCs originate from primitive erythromyeloid progenitors in the extraembryonic yolk sac ${ }^{31-34}$. A second wave of MCs appears together with the first definitive hematopoietic progenitors. The first two waves mainly contribute to connective tissue MCs (CTMC) and serosal-type $\mathrm{MCs}^{32}$. The third hematopoietic wave originates from the aorta-gonado-mesonephros region. Cells formed during this wave produce hematopoietic stem cells that exhibit MC-forming potential ${ }^{32}$. It was for a long time assumed that MCs develop from hematopoietic stem cells in the bone marrow ${ }^{35}$. However, it is now clear that bone marrow hematopoietic stem cells produce a fraction, but not all, MCs. Experiments also show that bone marrow-derived MCs mainly replenish the mucosal MC population postnatally ${ }^{32}$. However, there is a redundancy in the potential of the waves as bone marrow-derived MCs can reconstitute depleted skin-resident (connective tissue-type) MCs and populate the skin following inflammation ${ }^{36}$.

\section{From hematopoietic trees to differentiation landscapes}

The classic tree-like model that describes hematopoiesis assumes a stepwise loss of lineage potential with differentiation from hematopoietic stem cells to lineage-committed progenitors (Figure 2A). However, assignment of the MC differentiation trajectory to either the granulocyte-monocyte or the megakaryocyteerythrocyte branch is a controversial topic. Studies supporting the idea that MCs belong to either branch have been presented ${ }^{37-42}$. On a different angle, other investigations propose that MCs branch off early close to hematopoietic stem cells - and differentiate along a unique trajectory ${ }^{43,44}$.

Advances in high-throughput single-cell RNA sequencing and computational biology are now delineating the MC differentiation trajectory by suggesting a revision of the hematopoietic model ${ }^{45}$. The idea to reconstruct hematopoietic differentiation with single-cell transcriptomics is based on capturing a snapshot of single differentiating progenitors ${ }^{46}$. Such analysis reveals that differentiating cells traverse a continuous landscape of states, from multi- and bipotent progenitors to lineage committed cells (Figure 2B). A singlecell transcriptional landscape of bone marrow hematopoiesis in mouse shows that the MC developmental trajectory is positioned adjacent to the erythrocyte and basophil trajectories ${ }^{40,47}$. The MC and basophil trajectories are particularly close to each other ${ }^{47,48}$, which indicates the presence of a bipotent basophil-MC progenitor population, a finding that is recapitulated in single-cell fate assay experiments ${ }^{38,47-49}$. Cell fate assays of mouse bone marrow progenitors also verified that basophil/MC differentiation is closely coupled with erythropoiesis ${ }^{40}$. The combination of single-cell transcriptomics and lineage tracing provides even 
deeper insights into hematopoiesis with focus on MC differentiation. Tracing individually barcoded mouse hematopoietic progenitor cells duringin vitro culture confirms a coupling between $\mathrm{MC}$ and basophil fates as well as between MC and erythrocyte fates ${ }^{50}$. A link between basophil/MC progenitors and erythrocyte progenitors has also been proposed in human hematopoiesis ${ }^{51-54}$. Thus, single-cell RNA sequencing has revolutionized our understanding of MC differentiation. The data reveals an overall landscape of hematopoiesis and an association between the MC, erythrocyte and basophil granulocyte differentiation trajectories.

In summary, the landscape model of hematopoiesis unifies old and new theories of the MC differentiation field and constitutes a foundation for future research.

\section{Mast cell heterogeneity - how different are they from each other?}

MC heterogeneity was first described in the mid-60s by differences in histochemical staining features, and the concept of connective tissue mast cells (CTMCs) and mucosal mast cells (MMCs) was born ${ }^{55,56}$. In humans, different $\mathrm{MC}$ subpopulations have been defined by their protease content; those that express tryptase $\left(\mathrm{MC}_{\mathrm{T}}\right)$, tryptase and chymase $\left(\mathrm{MC}_{\mathrm{TC}}\right)$ and chymase only $\left(\mathrm{MC}_{\mathrm{C}}\right){ }^{57,58}$. The latter was, for a long time, controversial, and the presence of chymase-only positive MCs has remained ignored and virtually unstudied. The two distinct $\mathrm{MC}$ subpopulations, $\mathrm{MC}_{\mathrm{T}}$ and $\mathrm{MC}_{\mathrm{TC}}$, as well as the $\mathrm{MMC}$ and $\mathrm{CTMC}$, differ in their localization, mediator content and responsiveness to secretagogues ${ }^{59}$.

Besides dividing MCs into subpopulations based on their localization or protease content, there are also definitions of MCs being either constitutive or inducible, pro- or anti-inflammatory, or pro- or anti-tumorigenic (MC1 or MC2) 24,60,61. While the division into constitutive and inducible subpopulations might be related to the prenatal origin of the MC (see above), the latter is probably dependent on changes in the microenvironment during an inflammation. It is clear that MCs in different organs differ in their receptor and mediator expression, but also within a single tissue there is a considerable heterogeneity, e.g., among human lung $\mathrm{MC}_{\mathrm{T}}{ }^{62}$. Furthermore, the gene/protein expression within this $\mathrm{MC}_{\mathrm{T}}$ subpopulation changes during inflammatory responses ${ }^{63}$. A question to address is if these changes relate to different subtypes or a plasticity within the MC population.

The origin and development of different MC subpopulations have been enigmatic, but one clue was described recently as mentioned above ${ }^{33}$. For hematopoiesis in the adult, the question has been if there are several different MC progenitor populations in circulation, or if there is one progenitor population that has the capacity to differentiate and mature into any of the MC subtypes. In other words, is the heterogeneity driven by locally produced factors or is it driven by the recruitment of different types of designated progenitors? In a study where this question was addressed, the results suggested the existence of a common MC progenitor that gives rise to all MC subpopulations ${ }^{64}$. However, single cell RNA sequencing and single cell cultures will likely provide further proof and insights into this process.

The separation of MCs into different subpopulations based on their protease content or histochemical properties is rather simplistic. MCs show a great plasticity, and detailed analysis of protease expression in human lung MCs demonstrate a gradient in the expression of the different proteases in these cells ${ }^{65}$. Transcriptome comparisons of MCs from different mouse tissues with other immune cells revealed that MCs form a distinct population well separated from all other immune cells ${ }^{66}$. Within the MC population there was a substantial heterogeneity across tissues ${ }^{66}$. Similarly, proteome analysis of human skin and fat MCs confirmed the unique identity of MCs among immune lineages, including the granulocytes (neutrophils, eosinophils and basophils) 67. It will be interesting, when single MC RNA sequencing data from human tissues are available, to further decipher MC heterogeneity and plasticity. This will give further insight into MC heterogeneity and might provide a clearer view about differences among MCs within the same tissue.

\section{Mechanisms behind directions that mast cells take during their life cycle}

\section{Homing and migration}

$\mathrm{MC}$ progenitors circulating in the blood, in humans defined as $\mathrm{CD} 34^{+}, \mathrm{KIT}^{+}, \mathrm{Fc \varepsilon RI}^{+}$cells ${ }^{68}$, enter a specific tissue where they complete their maturation under the influence of locally produced factors. Surprisingly, 
the homing mechanisms for MC progenitors are still mostly unknown, except that it is a tissue specific process ${ }^{69-71}$. In addition to their basal homing, MC numbers clearly increase at sites of inflammation, such as in allergic rhinitis and asthma. This increase in $\mathrm{MC}$ numbers is likely a consequence of both increased proliferation and survival, as well as maturation of their progenitors recruited in response to chemoattractants 72,73. The fact that some chemokine receptors, such as CCR1, CXCR2 and CXCR4, are expressed on both progenitors and mature MCs suggests that MC accumulation at sites of inflammation may also involve relocalization of mature MCs within a specific tissue ${ }^{71-76}$.

\section{To migrate or to degranulate, that is the question}

To avoid loss of their munitions before reaching their final destination at inflamed sites, mature MCs need to be regulated to migrate, but not yet degranulate (Figure 3 ). This is a challenging requirement as some of the MC chemokines induce degranulation of basophils ${ }^{77}$ and synergize with secretagogues to potentiate MC degranulation ${ }^{78,79}$. Thus, it was proposed that chemokines may either elicit distinct signals in MCs, as opposed to basophils, or that MC SGs are linked to the cell cytoskeleton differently from the basophil granules ${ }^{77}$. Marked differences observed between the actin skeleton in migrating versus secreting MCs support the latter possibility ${ }^{80}$. Analysis of actin rearrangements following chemokine stimulation of MCs revealed an accumulation of pericentral actin clusters that prevent cell flattening and converge the SGs in the cell center ${ }^{80}$. By contrast, reduction in the actin mesh density characterizes the secretory actin phenotype. Thus, the migratory actin phenotype immobilizes the secretory granules by trapping them in the cell center, whereas the secretory actin phenotype supports mobility and exocytosis. Diaphanous-related formin, mDia1, appears to be key player in these actin rearrangements ${ }^{80}$ (Figure 3 ).

Kiss-and-run, full or partial exocytosis? The next question is how to degranulate

As MCs reach their destination and encounter a secretagogue, the secretory actin phenotype overrides the migratory actin phenotype, relieving the secretory constraints ${ }^{80}$. MCs then enter a state in which they can undergo exocytosis. This can take place in three different ways: i) individual SGs move to the plasma membrane where they dock and fuse with the membrane and release their full content; ii) by compound exocytosis where SGs fuse with each other, forming a channel through which they release their content; or iii) "kiss-and-run exocytosis" where SGs only transiently fuse with the membrane and release only part of their content ${ }^{81}$. Choosing the mode of exocytosis bears physiological significance, as the distinct features and dynamics of the different exocytic modes are associated with unique physiological responses ${ }^{82}$ (Figure 3 ). At the molecular level, two factors have been identified as critical for defining the degranulation pattern. The first is the enzyme IKK $\beta$, whose activity is required for the phosphorylation of the SNARE protein SNAP23, which is essential for SG fusion during compound exocytosis ${ }^{81-83}$. The second is the small GTPase Rab5, which plays a role in SG fusion during both their biogenesis ${ }^{84}$ and compound exocytosis ${ }^{85}$.

In conclusion, the underlying mechanisms that regulate MCs during their life cycle are only beginning to be clarified. They include mechanisms that ensure MC homing to destined tissues, recruitment to inflammatory areas, prevention of premature secretion and selection of the mode of exocytosis. Future studies will shed light on these mechanisms and the molecular entities involved.

\section{Mast Cells in Diseases}

MCs are involved in the initiation and perpetuation of a number of inflammatory conditions. These conditions range from those associated with an intrinsic or primary defect in MCs due to inherited or acquired polymorphisms and mutations within the MC compartment; to diseases where MCs are activated and recruited through an extrinsic mechanism such as formation of antigen-dependent and IgE-mediated MC activation; to clinical conditions where MCs are implicated through the release of MC mediators but where the mechanism of activation and recruitment is not well understood, thus "idiopathic" (Table I) ${ }^{86}$.

There are several well characterized molecular aberrancies affecting the MC compartment. Some are associated with recognized clinical diseases due to effects on MC proliferation and survival, MC reactivity or MC mediator production. Mastocytosis is perhaps the most widely known disease associated with a primary 
defect in the MC compartment. It is a clonal disease involving expansion of tissue MCs. Mastocytosis is most commonly associated with an acquired gain-of-function $K I T$ p.D816V missense variant, resulting in ligandindependent $\mathrm{MC}$ activation. This leads to both unrestrained growth of MCs and a lowered threshold for activation. Individuals with mastocytosis may present with flushing, pruritus, gastrointestinal complaints or systemic anaphylaxis that may occur following exposure to Hymenoptera venom or for unidentified reasons. Mastocytosis may present as cutaneous disease only, or as a systemic disease with or without cutaneous manifestations ${ }^{87}$.

A group of patients with recurrent anaphylaxis has clonal MCs as demonstrated by evidence of one or two minor criteria for mastocytosis including aberrant MC morphology, CD25 expression and/or presence of theKIT D816V point mutation. By consensus, such patients are currently said to have monoclonal MC activation syndrome (MMAS) ${ }^{88}$. If the marrow findings are observed in the absence of evidence of systemic $\mathrm{MC}$ activation, the term monoclonal MC disorder of uncertain significance has been suggested.

There are now a growing number of heritable genetic conditions that lead to increased MC reactivity. One such example is manifested as a physical urticaria. A missense substitution from cysteine to tyrosine (pC492Y) in the adhesion $\mathrm{G}$ protein-coupled receptor E2 (ADGRE2) is present in autosomal dominant vibratory urticaria (VU) characterized by localized hives and systemic manifestations in response to a local stimulus of frictional nature ${ }^{89}$. ADGRE2 (CD312) belongs to a large family of adhesion GPCRs generally with an extracellular domain facilitating interactions with proteins from the extracellular matrix. In this case, activation of MCs after a vibratory stimulus is evidenced by MC degranulation and increase in histamine in the venous blood from the affected areas. Thus, ADGRE2 functions as a mechanoreceptor and induces cutaneous MC degranulation. Although the physiological relevance of the limited MC responses to friction in normal individuals is not completely understood, possibilities are that ADGRE2 may alert both resident and immune cells to combat potential injury and wound healing. It may also play a role in pain modulation and perhaps help sense a parasite migrating through dermal tissues.

Hereditary alpha tryptasemia $(\mathrm{H} \alpha \mathrm{T})$ is a Mendelian genetic trait that bears mention as intrinsic to the MC and influencing mediator production. It is caused by increased TPSAB1 copy number encoding alphatryptase ${ }^{90}$. The MC tryptase loci in humans may encode $\alpha$ or $\beta$ tryptases (TPSAB1) and $\beta$-tryptases (TPSB2). One locus expresses either $\alpha$ or $\beta$-tryptase, while the other locus can express only $\beta$ tryptase, resulting in $\alpha: \beta$ tryptase gene ratios of $0: 4,1: 3$ or $2: 2$ in different individuals. Recent studies suggest that germline duplications and triplications of $\alpha$-tryptase are linked to subjects with dominantly inherited elevated basal serum tryptase levels which may affect up to $5 \%$ of the general population. Symptoms reported by up to two-thirds of these patients are suggestive of MC mediator release and include cutaneous flushing and irritable bowel syndrome ${ }^{91}$. Also reported are connective tissue abnormalities and dysautonomia. Individuals with multiple duplications show higher tryptase levels in serum, are more symptomatic, and have higher risk for severe anaphylaxis ${ }^{92,93}$. Recent mechanistic studies have demonstrated that unique enzymatic properties of alpha-tryptase containing heterotetrameric tryptases may contribute to this association ${ }^{94}$.

Extrinsic or secondary MC activation occurs primarily in allergic diseases, diseases associated with complement activation, and in association with activation of MCs through MRGPRX2. Symptoms may be infrequent to frequent and resultant disease sporadic or chronic depending on the activating mechanism. The immediate effects of MC degranulation, if localized to skin, include a weal and flare reaction or, in airways, contraction of airway smooth muscle, mucus secretion, and an increase in vascular permeability. If systemic, the results may include severe hypotension and extensive vascular leakage. The early responses often transition into a late phase reaction hours later associated with an influx of circulating cell types which promote further inflammation.

The idiopathic MC category includes urticaria, angioedema and anaphylaxis where there is no identifiable etiology, but where MC activation is documented through MC mediator release or evidence of MC degranulation in tissues involved. (Table I). The term idiopathic MC activation syndrome (Idiopathic MCAS) has been applied as a diagnosis for individuals who present with such episodic allergic-like signs and symptoms such as flushing, urticaria, diarrhea, and wheezing involving two or more organ systems, where the etiology 
is unknown ${ }^{95}$. Diagnostic criteria include response to anti-mediator therapy and an elevation in a validated urinary or serum marker of MC activation, such as serum tryptase with an episode. Primary and secondary MC disorders must be eliminated as possible causes of the clinical findings. However, the search should continue for the etiology of these idiopathic disorders including the possibility that MC activation may relate to a yet-to-be identified endogenous or environmental stimulus or an intrinsic MC defect resulting in a hyperactive $\mathrm{MC}$ phenotype.

\section{The development of mast cell-targeted treatments}

\section{Mast cell mediators as targets of treatment}

MC-targeted treatments are primarily developed for chronic urticaria (CU), mastocytosis, and allergies, because of the critical role that MCs play in their pathogenesis ${ }^{65,96}$. The evolution of MC-targeted treatments started, more than 70 years ago, with the development of drugs that inhibit the effects of individual MC mediators, first histamine, followed by prostaglandins and leukotrienes ${ }^{97}$. Modern antihistamines that act on the histamine 1 receptor are superior to first generation ones in their binding affinity, specificity, and risk/benefit profiles. Antihistamines that act on the histamine 4 receptor have shown promising results, and several such compounds are currently being developed for the treatment of MC-driven diseases. Recently a new approach to inhibit tryptase, the major MC protease, with an anti-tryptase antibody was tested in preclinical primate studies ${ }^{98}$. The therapeutic area is initially severe asthma where MCs are implicated ${ }^{99}$.

However, to target one MC mediator or one of its receptors comes with an inherent limitation, i.e., it prevents only the effects of one MC mediator or receptor. Activated MCs release many different mediators (acting on even more receptors) that are held to contribute to the development of signs and symptoms in patients with urticaria, mastocytosis and other MC-mediated diseases.

\section{Treatments that inhibit mast cell activation}

More recent attempts to target MCs therapeutically aim at the inhibition of activating signals and receptors (Figure 4). These include, for example, the high affinity receptor for IgE, FceRI, as well as the intracellular signals involved in translating receptor activation into degranulation and mediator release. Examples for the latter include Bruton's tyrosine kinase (BTK) and spleen associated tyrosine kinase (SYK). Inhibitors of BTK or SYK inhibit the degranulation of human MCs induced via FceRI. Two BTK inhibitors, Fenebrutinib and Remibrutinib, as well as the SYK inhibitor GSK2646264 are currently under development for the treatment of patients with CU.

In chronic spontaneous urticaria (CSU), the activation of skin MCs via FceRI, either by IgE to autoallergens or by autoantibodies to its alpha chain, is held to drive the development of signs and symptoms, itchy wheals and angioedema, in most patients ${ }^{100,101}$. Treatment with omalizumab, an anti-IgE antibody, is effective in $\mathrm{CSU}^{102}$ and prevents MC activation by reducing the levels of free IgE and FceRI expression. Newer anti-IgEs, including ligelizumab and GI-301, with higher affinity to IgE than omalizumab, are in clinical development ${ }^{103}$.

Several other activating signals and receptors are held to contribute to the activation and degranulation of MCs and, thereby, to the development of signs and symptoms of MC-driven diseases. These include the receptors for thymic stromal lymphopoietin (TSLP), IL-33, IL-4, IL-5, and complement C5a as well as MRGPRX2. For all of these receptors, inhibitory compounds (or compounds that inhibit their ligands) are currently in clinical development for MC-driven diseases, primarily $\mathrm{CU}^{104}$.

The benefit of targeting MC-activating signals, receptors, and pathways is that this approach protects from the release and, therefore, the effects of all MC mediators rather than only one. The limitation is that only one of many pathways of MC activation and degranulation is shut down. Other pathways are untouched, remain viable, and can lead to MC activation, as they often do in most MC-driven diseases.

Treatments that silence mast cells 
MCs express several inhibitory receptors ${ }^{105}$. Their ligand engagement inhibits MC activation and degranulation, thereby silencing MCs. Inhibitory MC receptors, including Siglec-8 and CD200Ra, and therapeutic antibodies that engage them are currently under development for CU (Figure 4). The Siglec-8-targeted antibody AK002 inhibits MC activation (and depletes eosinophils) and showed promising results in the treatment of omalizumab-naïve and omalizumab-refractory CSU, symptomatic dermographism, cholinergic urticaria, and systemic mastocytosis. The CD200Ra-targeted antibody LY3454738 is also under development for CU.

\section{Treatments that reduce mast cell numbers}

The KIT receptor is the key driver of MC differentiation, migration, proliferation and survival. The inhibition of KIT or SCF leads to MC apoptosis and reduced MC numbers. Compounds that target KIT or SCF are currently explored for the clinical development in MC-driven diseases including CU and mastocytosis ${ }^{106}$. For example, the antibody CDX-0159, which specifically binds the extracellular dimerization domain of KIT, was shown to induce profound and sustained suppression of plasma tryptase, indicative of systemic MC ablation. CDX-0159 is currently under development for CU. Examples for the development of oral KITtargeted treatments include Imatinib, Nilotinib, Midostaurin, and Avapritinib, all of which show efficacy in mastocytosis linked to reductions in MCs and/or serum tryptase levels.

\section{Animal models to study mast cell function}

Numerous types of animal models, primarily in the mouse, have been utilized throughout the years to outline the contribution of MCs in diverse pathological settings. In the first generation of such models, MC-deficiency in the mouse and rat was due to various mutations in Kit, i.e. the receptor for SCF. Since SCF is an essential growth factor for MCs, defects in Kit result in an essentially complete absence of MCs. However, KIT is also expressed by a number of other cell types, and it has therefore been challenging to ascertain that consequences of Kit defects are indeed explained by an impact on the MC niche as opposed to off-target effects on other populations (reviewed in ${ }^{107,108}$ ). To account for these issues, new mouse models of MCdeficiency, independent of Kit , have been developed (Table 2). These include mice where MC deficiency is driven by Cre recombinase expression under the control of MC-specific promoters. In one strategy, Cre recombinase was driven by the promoter for $M c p t 5$, a gene specifically expressed by CTMCs. These mice can then be crossed with $R 26^{D T A}$ mice, leading to constitutive MC deficiency due to MC-specific expression of diphtheria toxin (DT) ${ }^{109}$. Alternatively, the mice can be crossed with the $i D T R$ line, leading to MC-specific expression of the DT receptor; treatment of these mice with DT will thus lead to conditional depletion of MCs ${ }^{109}$. In another approach, MC deficiency was accomplished by inserting Cre under the control of the promoter for $\mathrm{Cpa3}$, a gene expressed predominantly by $\mathrm{MCs}^{110}$. This leads to constitutive $\mathrm{MC}$ depletion, apparently due to Cre-mediated genotoxicity, but also to a substantial reduction of basophils, the latter in agreement with studies showing that basophils express low levels of Cpa3. The Cpa3 promoter was also exploited to generate a mouse strain in which the Cre-LoxP recombination system was used for deletion of the gene coding for the anti-apoptotic factor Mcl-1. This led to an essentially complete absence of MCs but also to a major reduction in basophils ${ }^{111}$. MC depletion has also been accomplished in a model where the DT receptor gene was expressed under the control of a MC-specific IL-4 enhancer element ${ }^{112}$. Another strategy was to insert the DT receptor and bright red td-Tomato fluorescent protein genes into the gene coding for the $\beta$ chain of FceRI, which is expressed by basophils and MCs. This approach can be used for depletion of MCs and basophils and also as an elegant tool to visualize MCs/basophils in vivo ${ }^{113}$. More recently, a mouse line with reduced numbers of MMCs (CTMCs were not affected) was generated by expressing Cre under the control of the baboon- $\alpha$-chymase gene, and crossing these to mice with a floxed allele of Mcl- ${ }^{114}$.

By using these Kit -independent models of MC deficiency, important insight into the biological function of MCs has been obtained. As expected, the use of Kit -independent mouse models for MC-deficiency has firmly confirmed the essential role of MCs in allergic responses ${ }^{110,115}$. Moreover, recent studies have shown that MCs can have a role in melanoma dissemination ${ }^{116}$, cutaneous lymphoma ${ }^{117}$, collagen-induced arthritis ${ }^{118}$, bone fracture-associated inflammation ${ }^{119}$ and bone healing ${ }^{120}$. It was also demonstrated that MCs aggravate osteoarthritis ${ }^{121}$ and can mediate the detrimental impact of smoke components on asthmatic features ${ }^{122}$. Further, it has been demonstrated that MCs have a beneficial role in controlling bacterial clearance and 
promoting wound healing afterPseudomonas aeruginosa infection ${ }^{123}$, whereas a detrimental impact of MCs was seen in skin infection by Sporothrix schenckii ${ }^{124}$.

However, it is important to note that the use of these novel mouse models for MC deficiency has challenged some previous findings where a contribution of MCs in various pathologies has been implied. For example, recent findings based on Kit -independent mouse models for MC deficiency have questioned the role of MCs in certain models for autoimmune diseases ${ }^{110}$ and obesity ${ }^{125}$, as well as the proposed adjuvant activities of MCs ${ }^{118}$. Hence, a more nuanced view of how MCs are involved in pathological settings is currently emerging.

In addition to the various mouse models describe above, recent efforts have resulted in the generation of mice in which the MC niche is populated by human MCs. This was accomplished by transplanting human hematopoietic stem cells into NOD-scid IL2R- $\gamma^{-/-}$mice, and then promoting MC growth by administrating plasmids expressing human SCF, GM-CSF and IL-3. In these mice (denoted "humice" or NSG-SGM3), mature human MCs (co-expressing KIT and Fc $\varepsilon$ RI) were detected in multiple tissues. These "humice" have so far mainly been used to study the role of MCs in anaphylaxis and cutaneous drug reactions ${ }^{126-128}$, but also in the evaluation of new therapies, e.g., using a BTK inhibitor ${ }^{129}$. Moreover, functional human MCs could be developed from the bone marrow of these mice. Clearly, this humanized model has the potential to be used as a highly valuable tool to study human MC function.

\section{Table 1. Classification of mast cell mediated diseases*}

1. Primary (Intrinsic)

a. Mastocytosis

b. Monoclonal mast cell activation syndrome (MMAS)

c. Autosomal dominant vibratory urticaria (VU)

d. Hereditary alpha tryptasemia $(\mathrm{HaT})$

2. Secondary (Extrinsic)

a. Allergic disorders (FceRI mediated)

b. Mast cell activation through the high affinity IgG receptor (CD64)

c. MRGPRX2 mediated reactions

d. Diseases associated with complement activation (C3a, C5a)

3. Idiopathic\#

a. Anaphylaxis

b. Angioedema

c. Urticaria

d. Idiopathic mast cell activation syndrome (Idiopathic MCAS)

*See text for explanation. Focus is on human mast cell-associated diseases, examples only

\# When no inciting stimulus is identified

Table 2 . KIT-independent constitutive and inducible mouse models of MC deficiency.

Model, designation Principle

Constitutive

Mcpt5-Cre; R-DTA

Cre expression under the control of the Mcpt5 promoter; Cre-driven expression 


\begin{tabular}{ll}
\hline Model, designation & Principle \\
\hline $\mathrm{Cpa}^{\mathrm{Cre}+}$ ("Cre-Master") & Cre expression under the control of the Cpa3 promoter \\
$\mathrm{Cpa3-Cre;} \mathrm{Mcl-1} 1^{\mathrm{f} / \mathrm{fl}}$ ("Hello Kitty") & Mcl-1 deletion under the control of the Cpa3 promoter \\
Chm-Cre; Mcl-1 $1^{\mathrm{f} / \mathrm{fl}}$ & Mcl-1 deletion under the control of the baboon- $\alpha$-chymase gene \\
$\begin{array}{l}\text { Inducible } \\
\text { Mas-TRECK }\end{array}$ & DT receptor expressed under the control of a MC-specific IL-4 enhancer eleme \\
$\begin{array}{l}\text { Mcpt5-Cre; iDTR } \\
\text { Red mast cell and basophil (RMB) mouse }\end{array}$ & DT receptor expressed under the control of the Mcpt5 promoter \\
\hline
\end{tabular}

ND, not determined; DT, diphtheria toxin; CTMC, connective tissue-type MC; MMC, mucosal-type MC

\section{Box 1 Major milestone discoveries in the field of mast cell biology}

1863 Friedrich von Recklinghausen identify granulated cells in unstained connective tissues from different species

1878 Identification and description of mast cells by Paul Ehrlich ${ }^{130}$

1937 Heparin is present in mast cells ${ }^{131,132}$

1949 Description of systemic mastocytosis 133

1953 Mast cells contain histamine ${ }^{134}$

1956 Demonstration of the involvement of mast cells in anaphylaxis ${ }^{135}$

1966 Description of mast cell heterogeneity, i.e, mucosal mast cells and connective tissue mast cells ${ }^{55,56}$

1970 \& 1972 Slow reacting substance of anaphylaxis (SRS-A), later shown to be leukotrienes, was demonstrated to be released after IgE-receptor activation ${ }^{136,137}$

1977 Mast cells develop from bone marrow cells ${ }^{35}$

1981 Identification of tryptase as the predominant mast cell protease $\mathrm{e}^{138,139}$

1982 Prostaglandin D2 shown to be released from mast cells ${ }^{140}$

1987 Mast cells can express and secrete cytokines ${ }^{141,142}$

1989 Characterization of the high-affinity IgE-receptor ${ }^{143,144}$

1989 The central nervous system affects mast cell reactivity ${ }^{145}$

1990 Identification, cloning and characterization of $\mathrm{SCF}^{146}$

1992 Demonstration that SCF is the main growth and maturation factor for human mast cells ${ }^{147-150}$

1995 Identification of the D816V KIT mutation in systemic mastocytosis ${ }^{151}$

$2004 \& 2006$ Mast cell proteases detoxify endogenous peptides and venoms ${ }^{152,153}$

2015 Identification of MRGPRX2 as a receptor causing pseudoallergic reactions ${ }^{3}$

2018 Insight into the prenatal development of mast cells ${ }^{31,32}$

\section{Box 2 Future research perspectives}

* To determine if MCs from different hematopoietic waves exhibit distinct functions.

* To determine the developmental relationship between the MC trajectory and other myeloerythroid lineages. Is it consistent in health and disease? 
* To identify mechanisms behind an increase in MCs at a site of inflammation: local proliferation, survival and/or progenitor recruitment to the site of inflammation? What chemotactic factors drive MC progenitor recruitment in vivo?

* To get a better understanding of MC heterogeneity in different tissues and to define the mechanisms that regulate MC plasticity.

* To understand the mechanisms for differential release of MC mediators.

* To decipher the contribution of MCs and their mediators in diseases beyond primary MC diseases and allergy.

* To understand mast cell activation syndrome (MCAS). What are the mechanisms? How can it be diagnosed and treated?

* Development of drugs that selectively target MCs.

* Development of new KIT-independent MC deficient models (mouse, but also other species such as rat, ferret and guinea pig that might be better for specific diseases), in which MC functions and contributions to health and disease can be specifically investigated.

\section{Figure legends}

Figure 1. Mast cell activation pathways and release of mediators. Mast cells are endowed with a palette of receptors that can recognize endogenous and exogenous products and release different sets of mediators dependent on the receptor involved. Upon recognition mast cells react by releasing mediators through one or several pathways: 1) degranulation and release of granules containing e.g., histamine, heparin, proteases and cytokines; 2) release of newly synthesized lipid mediators such as PGD2, LTC4/D4/E4, TXA2 and 15-HETE; 3) release of de novo synthesized cytokines, chemokines, growth factors and interferons; 4) release of extracellular vesicles, e.g., exosomes, containing miRNA, mRNA and proteins.

Figure 2. Models representing mast cell differentiation in hematopoiesis. (A) The tree-like model represents hematopoiesis as a strict series of branching events, in which cell lineage potential is lost at defined checkpoints along differentiation from hematopoietic stem cells to lineage-committed cells. The position of the mast cell branch in this model is controversial. (B) The hematopoietic landscape model represents a continuum of single differentiating progenitors, in which there are multiple paths from hematopoietic stem cells to each lineage's entry point. Ba, basophil; Eo, eosinophil; Ery, erythrocyte, Gr, granulocyte, HSC, hematopoietic stem cell; Ly, lymphocyte; MC, mast cell; MK, megakaryocyte; Mo, monocyte, Neu, neutrophil.

Figure 3. Fate decisions in the life of the mast cell. Mast cell progenitors (MCp) in the bone marrow (1) are entering the blood stream and are recruited into the tissue (2). During this process the cells have to avoid premature degranulation (2). In the tissue (3) MCs can degranulate in three possible modes, either by full exocytosis, compound exocytosis or by kiss-and-run exocytosis.

Figure 4: MC-targeted treatments under development. Examples of treatments currently under development that target mast cell mediators, mast cell activating signals / receptors or their signaling molecules, inhibitory receptors, or mast cell depletion.

\section{REFERENCES}

1. Dahlin JS, Ekoff M, Grootens J, et al. KIT signaling is dispensable for human mast cell progenitor development. Blood 2017; 130(16): 1785-94.

2. Olivera A, Beaven MA, Metcalfe DD. Mast cells signal their importance in health and disease. J Allergy Clin Immunol 2018; 142(2): 381-93.

3. McNeil BD, Pundir P, Meeker S, et al. Identification of a mast-cell-specific receptor crucial for pseudoallergic drug reactions. Nature 2015; 519(7542): 237-41. 
4. Elst J, Sabato V, Faber MA, et al. MRGPRX2 and Immediate Drug Hypersensitivity: Insights from Cultured Human Mast Cells. Journal of investigational allergology \& clinical immunology 2020: 0.

5. Subramanian H, Gupta K, Ali H. Roles of Mas-related G protein-coupled receptor X2 on mast cellmediated host defense, pseudoallergic drug reactions, and chronic inflammatory diseases. J Allergy Clin Immunol 2016; 138(3): 700-10.

6. Kühn K, Kolkhir P, Babina M, et al. Mas-related G protein-coupled receptor X2 and its activators in dermatological allergies. J Allergy Clin Immunol 2020; Oct 15, Epub ahead of print.

7. Lunderius-Andersson C, Enoksson M, Nilsson G. Mast Cells Respond to Cell Injury through the Recognition of IL-33. Front Immunol 2012; 3: 120-30.

8. Babina M, Wang Z, Franke K, Guhl S, Artuc M, Zuberbier T. Yin-Yang of IL-33 in Human Skin Mast Cells: Reduced Degranulation, but Augmented Histamine Synthesis through p38 Activation. J Invest Dermatol2019; 139(7): 1516-25 e3.

9. Ohno T, Morita H, Arae K, Matsumoto K, Nakae S. Interleukin-33 in allergy. Allergy 2012; 67(10): 1203-14.

10. Ronnberg E, Ghaib A, Ceriol C, et al. Divergent Effects of Acute and Prolonged Interleukin 33 Exposure on Mast Cell IgE-Mediated Functions.Front Immunol 2019; 10: 1361.

11. Marshall JS, Portales-Cervantes L, Leong E. Mast Cell Responses to Viruses and Pathogen Products. Int J Mol Sci 2019; 20(17).

12. Wernersson S, Pejler G. Mast cell secretory granules: armed for battle. Nat Rev Immunol 2014; 14(7): 478-94.

13. Boyce JA. Mast cells and eicosanoid mediators: a system of reciprocal paracrine and autocrine regulation. Immunol Rev 2007; 217: 168-85.

14. Mukai K, Tsai M, Saito H, Galli SJ. Mast cells as sources of cytokines, chemokines, and growth factors. Immunol Rev 2018; 282(1): 121-50.

15. Moon TC, Befus AD, Kulka M. Mast cell mediators: their differential release and the secretory pathways involved. Front Immunol 2014; 5: 569.

16. Lecce M, Molfetta R, Milito ND, Santoni A, Paolini R. FcepsilonRI Signaling in the Modulation of Allergic Response: Role of Mast Cell-Derived Exosomes. Int J Mol Sci 2020; 21(15).

17. Skokos D, Le Panse S, Villa I, et al. Mast cell-dependent B and T lymphocyte activation is mediated by the secretion of immunologically active exosomes. J Immunol 2001; 166(2): 868-76.

18. Valadi H, Ekstrom K, Bossios A, Sjostrand M, Lee JJ, Lotvall JO. Exosome-mediated transfer of mRNAs and microRNAs is a novel mechanism of genetic exchange between cells. Nat Cell Biol 2007; 9(6): 654-9.

19. Kim DK, Cho YE, Komarow HD, et al. Mastocytosis-derived extracellular vesicles exhibit a mast cell signature, transfer KIT to stellate cells, and promote their activation. Proc Natl Acad Sci U S A 2018; 115(45): E10692-E701.

20. Siebenhaar F, Redegeld FA, Bischoff SC, Gibbs BF, Maurer M. Mast Cells as Drivers of Disease and Therapeutic Targets. Trends Immunol 2018; 39(2): 151-62.

21. Wilcock A, Bahri R, Bulfone-Paus S, Arkwright PD. Mast cell disorders: From infancy to maturity. Allergy 2019; 74(1): 53-63.

22. Galli SJ, Gaudenzio N, Tsai M. Mast Cells in Inflammation and Disease: Recent Progress and Ongoing Concerns. Annu Rev Immunol2020; 38: 49-77. 
23. Varricchi G, Marone G, Kovanen PT. Cardiac Mast Cells: Underappreciated Immune Cells in Cardiovascular Homeostasis and Disease. Trends Immunol 2020; 41(8): 734-46.

24. Varricchi G, de Paulis A, Marone G, Galli SJ. Future Needs in Mast Cell Biology. Int J Mol Sci 2019; 20(18).

25. Virk H, Arthur G, Bradding P. Mast cells and their activation in lung disease. Transl Res 2016; 174: 60-76.

26. Rathore AP, St John AL. Protective and pathogenic roles for mast cells during viral infections. Curr Opin Immunol 2020; 66: 74-81.

27. Piliponsky AM, Acharya M, Shubin NJ. Mast Cells in Viral, Bacterial, and Fungal Infection Immunity. Int J Mol Sci 2019; 20(12).

28. Jiao Q, Luo Y, Scheffel J, Zhao Z, Maurer M. The complex role of mast cells in fungal infections. Exp Dermatol 2019; 28(7): 749-55.

29. Nathan C. Points of control in inflammation. Nature 2002; 420: 846-52.

30. Dudeck A, Koberle M, Goldmann O, et al. Mast cells as protectors of health. J Allergy Clin Immunol 2019; 144(4S): S4-S18.

31. Gentek R, Ghigo C, Hoeffel G, et al. Hemogenic Endothelial Fate Mapping Reveals Dual Developmental Origin of Mast Cells. Immunity2018; 48(6): 1160-71 e5.

32. Li Z, Liu S, Xu J, et al. Adult Connective Tissue-Resident Mast Cells Originate from Late ErythroMyeloid Progenitors. Immunity2018; 49(4): 640-53 e5.

33. Nilsson G, Dahlin JS. New insights into the origin of mast cells. Allergy 2019; 74(4): 844-5.

34. Sonoda T, Hayashi C, Kitamura Y. Presence of mast cell precursors in the yolk sac of mice. Dev Biol 1983; 97(1): 89-94.

35. Kitamura Y, Shimada M, Hatanaka K, Miyano Y. Development of mast cells from grafted bone marrow cells in irradiated mice. Nature 1977; 268(5619): 442-3.

36. Weitzmann A, Naumann R, Dudeck A, Zerjatke T, Gerbaulet A, Roers A. Mast Cells Occupy Stable Clonal Territories in Adult Steady-State Skin.J Invest Dermatol 2020.

37. Ahmed N, Kunz L, Hoppe PS, et al. A Novel GATA2 Protein Reporter Mouse Reveals Hematopoietic Progenitor Cell Types. Stem Cell Reports 2020; 15(2): 326-39.

38. Arinobu Y, Iwasaki H, Gurish MF, et al. Developmental checkpoints of the basophil/mast cell lineages in adult murine hematopoiesis.Proc Natl Acad Sci U S A 2005; 102(50): 18105-10.

39. Inclan-Rico JM, Hernandez CM, Henry EK, et al. Trichinella spiralis-induced mastocytosis and erythropoiesis are simultaneously supported by a bipotent mast cell/erythrocyte precursor cell. PLoS pathogens 2020; 16(5): e1008579.

40. Tusi BK, Wolock SL, Weinreb C, et al. Population snapshots predict early haematopoietic and erythroid hierarchies. Nature 2018; 555(7694): 54-60.

41. Franco CB, Chen CC, Drukker M, Weissman IL, Galli SJ. Distinguishing mast cell and granulocyte differentiation at the single-cell level.Cell Stem Cell 2010; 6(4): 361-8.

42. Kirshenbaum AS, Goff JP, Semere T, Foster B, Scott LM, Metcalfe DD. Demonstration that human mast cells arise from a progenitor cell population that is CD34(+), c-kit $(+)$, and expresses aminopeptidase N (CD13). Blood 1999; 94(7): 2333-42. 
43. Motakis E, Guhl S, Ishizu Y, et al. Redefinition of the human mast cell transcriptome by deep-CAGE sequencing. Blood 2014; 123(17): e58-67.

44. Chen CC, Grimbaldeston MA, Tsai M, Weissman IL, Galli SJ. Identification of mast cell progenitors in adult mice. Proc Natl Acad Sci U S A 2005; 102(32): 11408-13.

45. Grootens J, Ungerstedt JS, Nilsson G, Dahlin JS. Deciphering the differentiation trajectory from hematopoietic stem cells to mast cells. Blood Adv 2018; 2(17): 2273-81.

46. Laurenti E, Gottgens B. From haematopoietic stem cells to complex differentiation landscapes. Nature 2018; 553(7689): 418-26.

47. Dahlin JS, Hamey FK, Pijuan-Sala B, et al. A single-cell hematopoietic landscape resolves 8 lineage trajectories and defects in Kit mutant mice. Blood 2018; 131(21): e1-e11.

48. Hamey FK, Lau WWY, Kucinski I, et al. Single-cell molecular profiling provides a high-resolution map of basophil and mast cell development. Allergy 2020; Oct 30, Epub ahead of print.

49. Qi X, Hong J, Chaves L, et al. Antagonistic regulation by the transcription factors C/EBPalpha and MITF specifies basophil and mast cell fates. Immunity 2013; 39(1): 97-110.

50. Weinreb C, Rodriguez-Fraticelli A, Camargo FD, Klein AM. Lineage tracing on transcriptional landscapes links state to fate during differentiation. Science 2020; 367(6479).

51. Grootens J, Ungerstedt JS, Wu C, Hamberg Levedahl K, Nilsson G, Dahlin JS. CD203c distinguishes the erythroid and mast cell-basophil differentiation trajectories among human FcepsilonRI $(+)$ bone marrow progenitors. Allergy 2020; 75(1): 211-4.

52. Drissen R, Thongjuea S, Theilgaard-Monch K, Nerlov C. Identification of two distinct pathways of human myelopoiesis. Sci Immunol 2019; 4(35).

53. Bian Z, Gong Y, Huang T, et al. Deciphering human macrophage development at single-cell resolution. Nature 2020; 582(7813): 571-6.

54. Popescu DM, Botting RA, Stephenson E, et al. Decoding human fetal liver haematopoiesis. Nature 2019; 574(7778): 365-71.

55. Enerbäck L. Mast cells in rat gastrointestinal mucosa. I. Effects of fixation. Acta Pathol Microbiol Scand 1966; 66: 289-302.

56. Enerbäck L. Mast cells in rat gastrointestinal mucosa. II. Dye-binding and metachromatic properties. Acta Pathol Microbiol Scand 1966; 66: 302-12.

57. Irani AA, Schechter NM, Craig SS, DeBlois G, Schwartz LB. Two types of human mast cells that have distinct neutral protease compositions.Proc Natl Acad Sci USA 1986; 83(4464): 4464-8.

58. Weidner N, Austen KF. Ultrastructural and immunohistochemical characterization of normal mast cells at multiple body sites. $J$ Invest Dermatol 1991; 96(3 Suppl): 26S-30S; discussion S-1S, 60S-5S.

59. Lowman MA, Rees PH, Benyon RC, Church MK. Human mast cell heterogeneity: Histamine release from mast cells dispersed from skin, lung adenoids, tonsils, and colon in response to IgE-dependent and nonimmunologic stimuli. J Allergy Clin Immunol 1988; 81(590): 590-7.

60. Derakhshan T, Samuchiwal SK, Hallen N, et al. Lineage-specific regulation of inducible and constitutive mast cells in allergic airway inflammation. J Exp Med 2021; 218(1).

61. Bankova LG, Dwyer DF, Liu AY, Austen KF, Gurish MF. Maturation of mast cell progenitors to mucosal mast cells during allergic pulmonary inflammation in mice. Mucosal Immunol 2015; 8(3): 596-606.

62. Andersson CK, Mori M, Bjermer L, Lofdahl CG, Erjefalt JS. Novel Site-Specific Mast Cell Subpopulations in the Human Lung. Thorax 2009; 64: 297-305. 
63. Andersson CK, Mori M, Bjermer L, Lofdahl CG, Erjefalt JS. Alterations in lung mast cell populations in patients with chronic obstructive pulmonary disease. Am J Respir Crit Care Med 2010; 181(3): 206-17.

64. Maaninka K, Lappalainen J, Kovanen PT. Human mast cells arise from a common circulating progenitor. J Allergy Clin Immunol 2013; 132(2): 463-9 e3.

65. Hallgren J, Hellman L, Maurer M, et al. Novel aspects of mast cell and basophil function: Highlights from the 9th meeting of the European Mast Cell and Basophil Research Network (EMBRN)-A Marcus Wallenberg Symposium. Allergy 2020; 75(3): 707-8.

66. Dwyer DF, Barrett NA, Austen KF, Immunological Genome Project C. Expression profiling of constitutive mast cells reveals a unique identity within the immune system. Nat Immunol 2016; 17(7): 878-87.

67. Plum T, Wang X, Rettel M, Krijgsveld J, Feyerabend TB, Rodewald HR. Human Mast Cell Proteome Reveals Unique Lineage, Putative Functions, and Structural Basis for Cell Ablation. Immunity 2020; 52(2): 404-16 e5.

68. Dahlin JS, Malinovschi A, Ohrvik H, et al. Lin- CD34hi CD117int/hi FcepsilonRI+ cells in human blood constitute a rare population of mast cell progenitors. Blood 2016; 127(4): 383-91.

69. Gurish MF, Tao H, Abonia JP, et al. Intestinal mast cell progenitors require CD49dbeta7 (alpha4beta7 integrin) for tissue-specific homing. $J$ Exp Med 2001; 194(9): 1243-52.

70. Hallgren J, Gurish MF. Mast cell progenitor trafficking and maturation. Advances in experimental medicine and biology 2011; 716: 14-28.

71. Salomonsson M, Dahlin JS, Ungerstedt J, Hallgren J. Localization-Specific Expression of CCR1 and CCR5 by Mast Cell Progenitors. Front Immunol 2020; 11: 321.

72. Halova I, Draberova L, Draber P. Mast cell chemotaxis - chemoattractants and signaling pathways. Front Immunol 2012; 3: 119.

73. Juremalm M, Nilsson G. Chemokine receptor expression by mast cells. Chem Immunol Allergy 2005; 87: $130-44$.

74. Nilsson G, Mikovits J, Metcalfe DD, Taub DD. Mast cell migratory response to IL-8 is mediated through interaction with chemokine receptor CXC-2/IL-8RB. Blood 1999; 93: 2791-7.

75. Juremalm M, Hjertson M, Olsson N, Harvima I, Nilsson K, Nilsson G. The chemokine receptor CXCR4 is expressed within the mast cell lineage and its ligand SDF-1a acts as a mast cell chemotaxin. Eur J Immunol 2000; 30: 3614-22.

76. Juremalm M, Olsson N, Nilsson G. Selective CCL5/RANTES-induced mast cell migration through interactions with chemokine receptors CCR1 and CCR4. Biochem Biophys Res Commun 2002; 297(3): 480-5.

77. Taub D, Dastych J, Inamura N, et al. Bone marrow-derived murine mast cells migrate, but do not degranulate, in response to chemokines.J Immunol 1995; 154: 2393-402.

78. Toda M, Dawson M, Nakamura T, et al. Impact of engagement of FceRI and CC chemokine receptor 1 on mast cell activation and motility. The Journal of biological chemistry 2004; 279(46): 48443-8.

79. Nguyen M, Solle M, Audoly LP, et al. Receptors and signaling mechanisms required for prostaglandin E2-mediated regulation of mast cell degranulation and IL-6 production. J Immunol 2002; 169(8): 4586-93.

80. Klein O, Krier-Burris RA, Lazki-Hagenbach P, et al. Mammalian diaphanous-related formin 1 (mDia1) coordinates mast cell migration and secretion through its actin-nucleating activity. J Allergy Clin Immunol 2019; 144(4): 1074-90.

81. Pickett JA, Edwardson JM. Compound exocytosis: mechanisms and functional significance. Traffic 2006; 7(2): 109-16. 
82. Gaudenzio N, Sibilano R, Marichal T, et al. Different activation signals induce distinct mast cell degranulation strategies. J Clin Invest 2016; 126(10): 3981-98.

83. Hepp R, Puri N, Hohenstein AC, Crawford GL, Whiteheart SW, Roche PA. Phosphorylation of SNAP-23 regulates exocytosis from mast cells. The Journal of biological chemistry 2005; 280(8): 6610-20.

84. Azouz NP, Zur N, Efergan A, et al. Rab5 is a novel regulator of mast cell secretory granules: impact on size, cargo, and exocytosis. J Immunol 2014; 192(9): 4043-53.

85. Klein O, Roded A, Zur N, et al. Rab5 is critical for SNAP23 regulated granule-granule fusion during compound exocytosis. Sci Rep 2017; 7(1): 15315.

86. Akin C, Valent P, Metcalfe DD. Mast cell activation syndrome: Proposed diagnostic criteria. J Allergy Clin Immunol 2010; 126(6): 1099-104 e4.

87. Valent P, Akin C, Hartmann K, et al. Advances in the Classification and Treatment of Mastocytosis: Current Status and Outlook toward the Future. Cancer Res 2017; 77(6): 1261-70.

88. Metcalfe DD, Gotlib J. Systemic mastocytosis. In: Greer JP, Arber DA, Applebaum FR, et al., eds. Wintrobe's Clinical Hematology, Fourteenth edition Philadelphia: Wolters Kluwer 2019: 1793-808.

89. Boyden SE, Desai A, Cruse G, et al. Vibratory Urticaria Associated with a Missense Variant in ADGRE2. $N$ Engl J Med 2016; 374(7): 656-63.

90. Lyons JJ, Yu X, Hughes JD, et al. Elevated basal serum tryptase identifies a multisystem disorder associated with increased TPSAB1 copy number. Nat Genet 2016; 48(12): 1564-9.

91. Robey RC, Wilcock A, Bonin H, et al. Hereditary Alpha-Tryptasemia: UK Prevalence and Variability in Disease Expression. J Allergy Clin Immunol Pract 2020.

92. Lyons JJ, Chovanec J, O'Connell MP, et al. Heritable risk for severe anaphylaxis associated with increased alpha-tryptase-encoding germline copy number at TPSAB1. J Allergy Clin Immunol 2020; online ahead of print.

93. Greiner G, Sprinzl B, Gorska A, et al. Hereditary alpha tryptasemia is a valid genetic biomarker for severe mediator-related symptoms in mastocytosis. Blood 2020.

94. Le QT, Lyons JJ, Naranjo AN, et al. Impact of naturally forming human alpha/beta-tryptase heterotetramers in the pathogenesis of hereditary alpha-tryptasemia. J Exp Med 2019; 216(10): 2348-61.

95. Valent P, Akin C, Bonadonna P, et al. Proposed Diagnostic Algorithm for Patients with Suspected Mast Cell Activation Syndrome. J Allergy Clin Immunol Pract 2019; 7(4): 1125-33 e1.

96. Harvima IT, Levi-Schaffer F, Draber P, et al. Molecular targets on mast cells and basophils for novel therapies. J Allergy Clin Immunol 2014; 134(3): 530-44.

97. Church MK, Maurer M. Antihistamines. Chem Immunol Allergy2014; 100: 302-10.

98. Maun HR, Jackman JK, Choy DF, et al. An Allosteric Anti-tryptase Antibody for the Treatment of Mast Cell-Mediated Severe Asthma.Cell 2019; 179(2): 417-31 e19.

99. Pejler G. The emerging role of mast cell proteases in asthma.Eur Respir $J$ 2019; 54(4).

100. Maurer M, Eyerich K, Eyerich S, et al. Urticaria: Collegium Internationale Allergologicum (CIA) Update 2020. Int Arch Allergy Immunol 2020; 181(5): 321-33.

101. Altrichter S, Zampeli V, Ellrich A, Zhang K, Church MK, Maurer M. IgM and IgA in addition to IgG autoantibodies against FcvarepsilonRIalpha are frequent and associated with disease markers of chronic spontaneous urticaria. Allergy 2020; (online ahead of print). 
102. Maurer M, Rosen K, Hsieh HJ, et al. Omalizumab for the treatment of chronic idiopathic or spontaneous urticaria. N Engl J Med 2013; 368(10): 924-35.

103. Maurer M, Gimenez-Arnau AM, Sussman G, et al. Ligelizumab for Chronic Spontaneous Urticaria. $N$ Engl J Med 2019; 381(14): 1321-32.

104. Kolkhir P, Altrichter S, Munoz M, Hawro T, Maurer M. New treatments for chronic urticaria. Ann Allergy Asthma Immunol 2020; 124(1): 2-12.

105. Caproni M, Bianchi B, D'Elios MM, De Carli M, Amedei A, Fabbri P. In vivo relevance of CD30 in atopic dermatitis. Allergy 1997; 52: 1063-70.

106. Valent P, Akin C, Hartmann K, et al. Mast cells, a unique hematologic lineage and cell system: From Paul Ehrlich to precision medicine. Theranostics 2020; 10(23): 10743-68.

107. Rodewald HR, Feyerabend TB. Widespread immunological functions of mast cells: fact or fiction? Immunity 2012; 37(1): 13-24.

108. Reber LL, Marichal T, Galli SJ. New models for analyzing mast cell functions in vivo. Trends Immunol 2012; 33(12): 613-25.

109. Dudeck A, Dudeck J, Scholten J, et al. Mast cells are key promoters of contact allergy that mediate the adjuvant effects of haptens.Immunity 2011; 34(6): 973-84.

110. Feyerabend TB, Weiser A, Tietz A, et al. Cre-mediated cell ablation contests mast cell contribution in models of antibody- and T cell-mediated autoimmunity. Immunity 2011; 35(5): 832-44.

111. Lilla JN, Chen CC, Mukai K, et al. Reduced mast cell and basophil numbers and function in Cpa3-Cre; Mcl-1fl/fl mice. Blood 2011; 118(26): 6930-8.

112. Otsuka A, Kubo M, Honda T, et al. Requirement of interaction between mast cells and skin dendritic cells to establish contact hypersensitivity. PloS one 2011; 6(9): e25538.

113. Dahdah A, Gautier G, Attout T, et al. Mast cells aggravate sepsis by inhibiting peritoneal macrophage phagocytosis. J Clin Invest2014; 124(10): 4577-89.

114. Luo Y, Meyer N, Jiao Q, et al. Chymase-Cre; Mcl-1(fl/fl) Mice Exhibit Reduced Numbers of Mucosal Mast Cells. Front Immunol2019; 10: 2399.

115. Hoppe A, Katsoulis-Dimitriou K, Edler HJ, Dudeck J, Drube S, Dudeck A. Mast cells initiate the vascular response to contact allergens by sensing cell stress. J Allergy Clin Immunol 2020; 145(5): 1476-9 e3.

116. Ohrvik H, Grujic M, Waern I, et al. Mast cells promote melanoma colonization of lungs. Oncotarget 2016; 7(42): 68990-9001.

117. Rabenhorst A, Schlaak M, Heukamp LC, et al. Mast cells play a protumorigenic role in primary cutaneous lymphoma. Blood 2012; 120(10): 2042-54.

118. Schubert N, Dudeck J, Liu P, et al. Mast cell promotion of T cell-driven antigen-induced arthritis despite being dispensable for antibody-induced arthritis in which $\mathrm{T}$ cells are bypassed.Arthritis Rheumatol 2015; 67(4): 903-13.

119. Kroner J, Kovtun A, Kemmler J, et al. Mast Cells Are Critical Regulators of Bone Fracture-Induced Inflammation and Osteoclast Formation and Activity. J Bone Miner Res 2017; 32(12): 2431-44.

120. Ramirez-GarciaLuna JL, Chan D, Samberg R, et al. Defective bone repair in mast cell-deficient Cpa3Cre/+ mice. PloS one 2017; 12(3): e0174396.

121. Wang Q, Lepus CM, Raghu H, et al. IgE-mediated mast cell activation promotes inflammation and cartilage destruction in osteoarthritis. Elife 2019; 8 . 
122. Yu M, Mukai K, Tsai M, Galli SJ. Thirdhand smoke component can exacerbate a mouse asthma model through mast cells. J Allergy Clin Immunol 2018; 142(5): 1618-27 e9.

123. Zimmermann C, Troeltzsch D, Gimenez-Rivera VA, et al. Mast cells are critical for controlling the bacterial burden and the healing of infected wounds. Proc Natl Acad Sci U S A 2019; 116(41): 20500-4.

124. Jiao Q, Luo Y, Scheffel J, et al. Skin Mast Cells Contribute to Sporothrix schenckii Infection. Front Immunol 2020; 11: 469.

125. Gutierrez DA, Muralidhar S, Feyerabend TB, Herzig S, Rodewald HR. Hematopoietic Kit Deficiency, rather than Lack of Mast Cells, Protects Mice from Obesity and Insulin Resistance. Cell Metab 2015; 21(5): $678-91$.

126. Mencarelli A, Gunawan M, Yong KSM, et al. A humanized mouse model to study mast cells mediated cutaneous adverse drug reactions. J Leukoc Biol 2020; 107(5): 797-807.

127. Bryce PJ, Falahati R, Kenney LL, et al. Humanized mouse model of mast cell-mediated passive cutaneous anaphylaxis and passive systemic anaphylaxis. J Allergy Clin Immunol 2016; 138(3): 769-79.

128. Burton OT, Stranks AJ, Tamayo JM, Koleoglou KJ, Schwartz LB, Oettgen HC. A humanized mouse model of anaphylactic peanut allergy.J Allergy Clin Immunol 2017; 139(1): 314-22 e9.

129. Dispenza MC, Krier-Burris RA, Chhiba KD, Undem BJ, Robida PA, Bochner BS. Bruton's tyrosine kinase inhibition effectively protects against human IgE-mediated anaphylaxis. J Clin Invest 2020; 130(9): 4759-70.

130. Ehrlich P. Beiträge zur Theorie und Praxis der Histologischen Färbung. Leipzig: Leipzig University; 1878.

131. Jorpes JE, Holmgren H, Wilander O. Ueber das vorkommen van heparin in den gefasswanden und in den augen. Ztschr mikr -anat Forsch1937; 42: 279-301.

132. Holmgren H, Wilander O. Beitrag zur kenntnis der chemie und funktion der ehr - lichschen mastzellen Ztschr mikr -anat Forsch1937; 42: 242-78.

133. Ellis JM. Urticaria pigmentosa; a report of a case with autopsy.Arch Pathol (Chic) 1949; 48(5): 426-35.

134. Riley JF, West GB. The presence of histamine in tissue mast cells.J Physiol (London) 1953; 120: 528-37.

135. Mota I, Vugman I. Effects of anaphylactic shock and compound 48/80 on the mast cells of the guinea pig lung. Nature 1956; 177(4505): 427-9.

136. Ishizaka T, Ishizaka K, Orange RP, Austen KF. The capacity of human immunoglobulin E to mediate the release of histamine and slow reacting substance of anaphylaxis (SRS-A) from monkey lung. J Immunol1970; 104(2): 335-43.

137. Ishizaka T, Ishizaka K, Tomioka H. Release of histamine and slow reacting substance of anaphylaxis (SRS-A) by IgE-anti-IgE reactions on monkey mast cells. J Immunol 1972; 108(2): 513-20.

138. Schwartz LB, Lewis RA, Austen KF. Tryptase from human pulmonary mast cells: Purification and characterization. J Biol Chem 1981; 256(11939): 11939-43.

139. Schwartz LB, Lewis RA, Seldin D, Austen KF. Acid hydrolases and tryptase from secretory granules of dispersed human lung mast cells. J Immunol 1981; 126: 1290-4.

140. Lewis RA, Soter NA, Diamond PT, Austen KF, Oates JA, Roberts LJ, 2nd. Prostaglandin D2 generation after activation of rat and human mast cells with anti-IgE. J Immunol 1982; 129(4): 1627-31.

141. Brown MA, Pierce JH, Watson CJ, Falco J, Ihle JN, Paul WE. B cell stimulatory factor-1/interleukin-4 mRNA is expressed by normal and transformed mast cells. Cell 1987; 50: 809-18. 
142. Young J-E, Liu C-C, Butler G, Cohn ZA, Galli SJ. Identification, purification, and characterization of a mast cell-associated cytolytic factor related to tumor necrosis factor. Proc Natl Acad Sci USA1987; 84: 9175-9.

143. Blank U, Ra C, Miller L, White K, Metzger H, Kinet JP. Complete structure and expression in transfected cells of high affinity IgE receptor. Nature 1989; 337(6203): 187-9.

144. Miller L, Blank U, Metzger H, Kinet JP. Expression of high-affinity binding of human immunoglobulin E by transfected cells. Science1989; 244(4902): 334-7.

145. MacQueen G, Marshall J, Perdue M, Siegel S, Bienenstock J. Pavlovian conditioning of rat mucosal mast cells to secrete rat mast cell protease II. Science 1989; 243(4887): 83-5.

146. Witte ON. Steel locus defines new multipotent growth factor. Cell 1990; 63(1): 5-6.

147. Irani AA, Nilsson G, Miettinen U, et al. Recombinant human stem cell factor stimulates differentiation of mast cells from dispersed human fetal liver cells. Blood 1992; 80(3009): 3009-21.

148. Kirshenbaum AS, Goff JP, Kessler SW, Mican JM, Zsebo KM, Metcalfe DD. Effect of IL-3 and stem cell factor on the apperance of human basophils and mast cells from CD34+ pluripotent progenitor cells. $J$ Immunol 1992; 148: 772-7.

149. Valent P, Spanblöchl E, Sperr WR, et al. Induction of differentiation of human mast cells from bone marrow and peripheral blood mononuclear cells by recombinant human stem cell factor/kit-ligand in longterm culture. Blood 1992; 80(2237): 2237-45.

150. Mitsui H, Furitsu T, Dvorak AM, et al. Development of human mast cells from umbilical cord blood cells by recombinant human and murine c-kit ligand. Proc Natl Acad Sci USA 1993; 90(735): 735-9.

151. Nagata H, Worobec AS, Oh CK, et al. Identification of a point mutation in the catalytic domain of the protooncogene c-kit in peripheral blood mononuclear cells of patients who have mastocytosis with an associated hematologic disorder. Proc Natl Acad Sci USA1995; 92: 10560-4.

152. Maurer M, Wedemeyer J, Metz M, et al. Mast cells promote homeostasis by limiting endothelin-1induced toxicity. Nature 2004; 432(7016): 512-6.

153. Metz M, Piliponsky AM, Chen CC, et al. Mast cells can enhance resistance to snake and honeybee venoms. Science 2006; 313(5786): 526-30. 


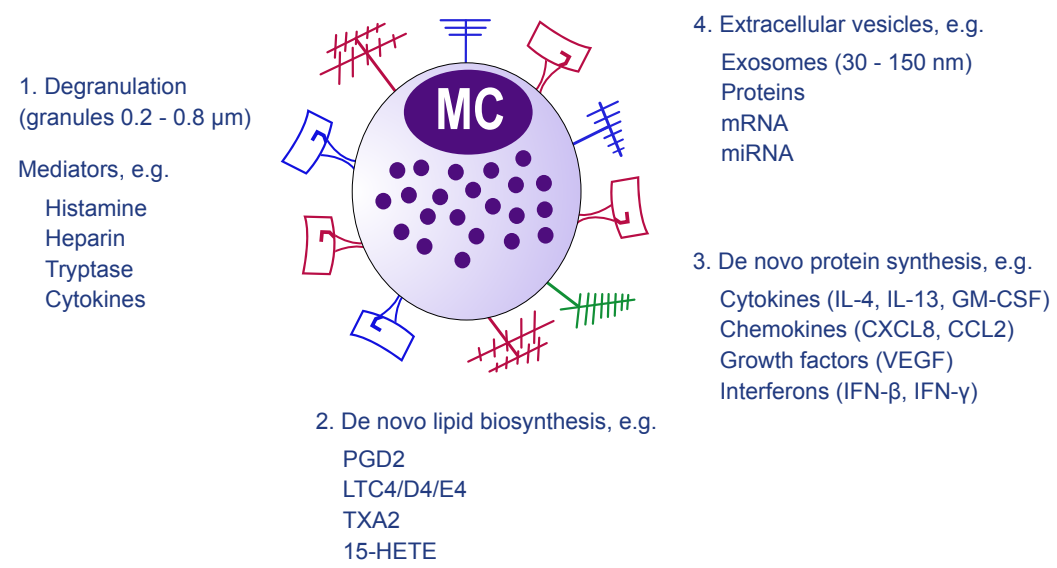

Figure 1_Nilsson et al. 
A

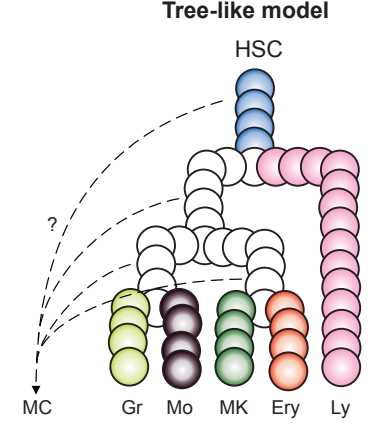

B

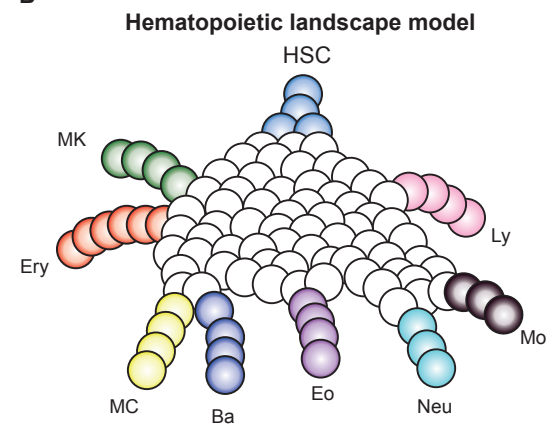




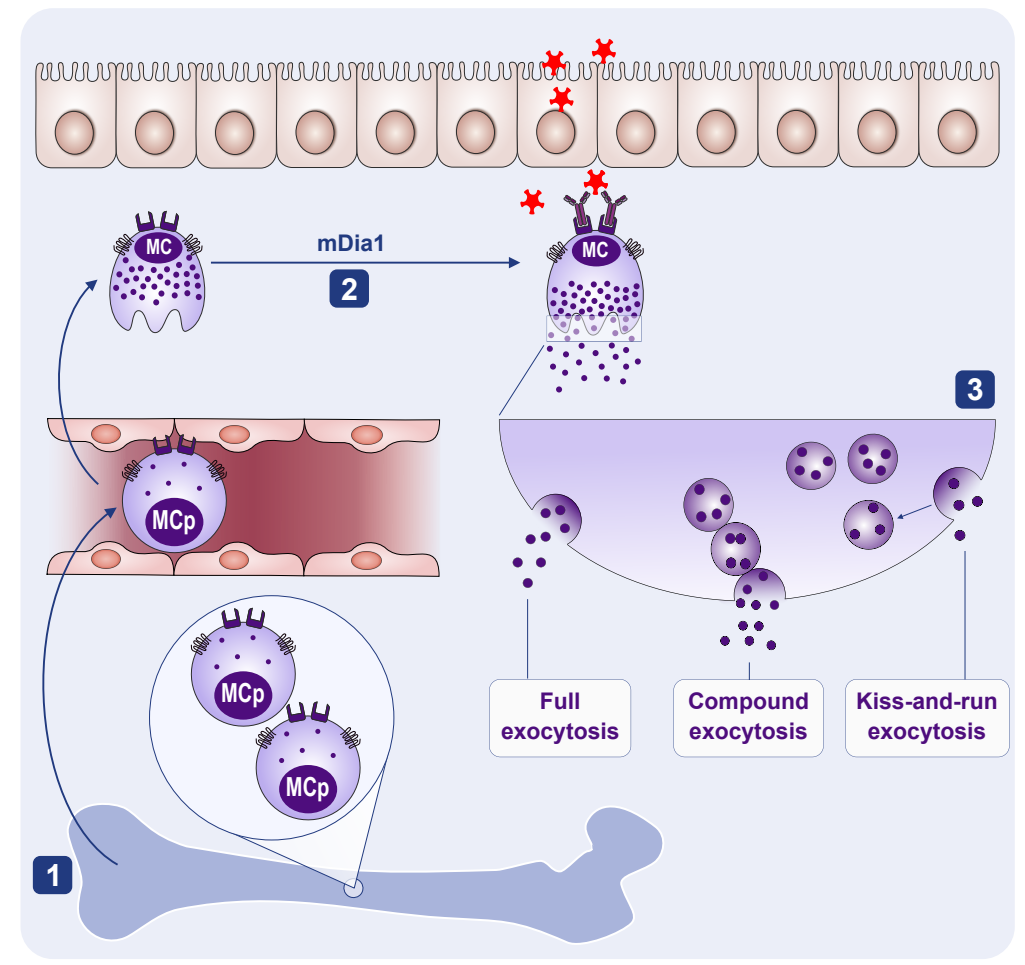

Figure 3_Nilsson et al. 

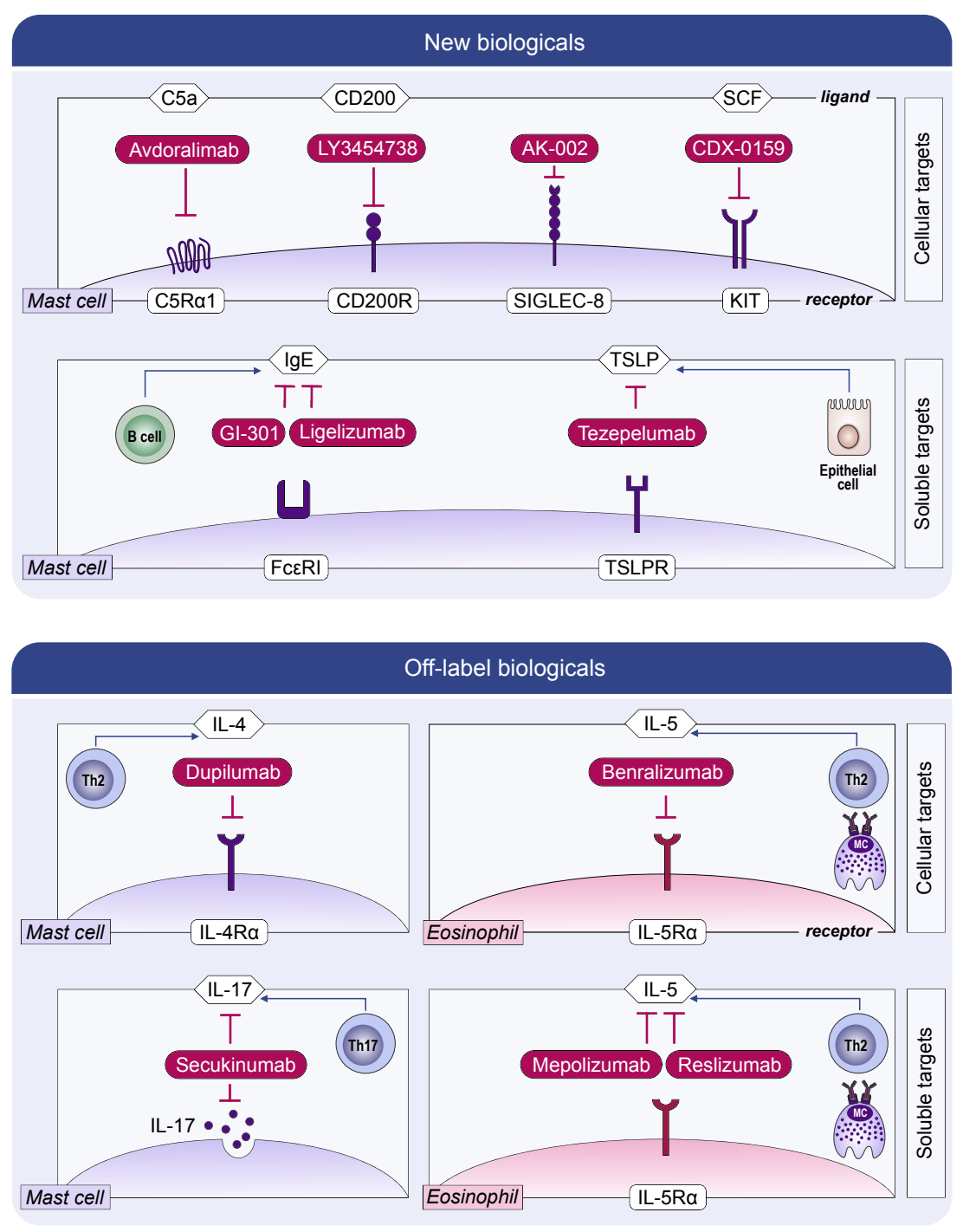

Figure 4_Nilsson et al. 